\title{
Path to 1-MW at J-PARC Rapid Cycling Synchrotron
}

\author{
Kazami Yamamoto \\ Japan Proton Accelerator Research Complex (J-PARC) Center, Japan Atomic Energy Agency (JAEA), Japan
}

Copyright $(2017$ by authors, all rights reserved. Authors agree that this article remains permanently open access under the terms of the Creative Commons Attribution License 4.0 International License

\begin{abstract}
The accelerator system at Japan Proton Accelerator Research Complex (J-PARC) has been operational since May 2008 and has mainly been used to perform physics experiments. The accelerator system consists of a Linac, a Rapid Cycling Synchrotron (RCS), and a Main Ring Synchrotron. The originally designed RCS injection energy is $400 \mathrm{MeV}$, but the first operation started at $181 \mathrm{MeV}$. New acceleration cavities were installed in J-PARC Linac during the summer shutdown of 2013, and user operation by the Material and Life science Facility (MLF) at the injection energy of $400 \mathrm{MeV}$ was started from February 2014. Post beam commissioning of $400 \mathrm{MeV}$ injection energy, beam loss was small enough, and we established $300 \mathrm{~kW}$ continuous operation. Subsequently, the peak current of the Linac was increased from $30 \mathrm{~mA}$ to $50 \mathrm{~mA}$. This upgrade enabled us to try 1-MW beam acceleration. Finally, after some additional improvements, we successfully accelerated 1-MW equivalent protons.
\end{abstract}

Keywords J-PARC, Proton Accelerator, High Intensity

\section{Introduction}

The Japan Proton Accelerator Research Complex (J-PARC) is a facility for performing various physics experiments. J-PARC facilities were constructed at the Tokai site of Japan Atomic Energy Agency (JAEA). The accelerator complex consists of a $400 \mathrm{MeV}$ Linac, a $3 \mathrm{GeV}$ Rapid-Cycling Synchrotron (RCS), and a Main Ring synchrotron (MR) [1]. The RCS delivers a $3 \mathrm{GeV}$ high-power proton beam to the Material and Life science Facility (MLF) and MR. Beam commissioning of the Linac started in November 2006 [2-4]. Construction of other accelerators and experimental facilities continued thereafter, and the RCS started to deliver a proton beam to the MLF in May 2008 [5]. User operation of MLF started in December 2008 [6], and beam power was increased gradually. However, the great east earthquake caused severe damage to all J-PARC facilities in March 2011. We completed the recovery work in only nine months and restarted user operation [7]. After the earthquake, we smoothly increased the output power, and user operation at $300 \mathrm{~kW}$ was started at the end of 2012 [8]. However, it was necessary to improve the Linac and the RCS to increase output power. Then, the acceleration energy of the Linac was raised to $400 \mathrm{MeV}$ by installing a new acceleration cavity in the summer of 2013. The injection system of the RCS was also upgraded simultaneously to accept $400 \mathrm{MeV}$ injection beam. In addition, the front end was replaced in the summer of 2014 to increase the beam current of $50 \mathrm{~mA}$ to achieve 1-MW beam acceleration.

\section{RCS Injection Energy Upgrade in 2013}

\subsection{Linac}

To increase the output power of the RCS, the acceleration energy of the Linac was increased from $181 \mathrm{MeV}$ to $400 \mathrm{MeV}$ at the first set-out. This energy upgrade aims to mitigate the effect of space charge in the RCS injection process and to reduce beam loss. Therefore, the ACS (Annular-ring Coupled Structure) cavity was developed [9, 10]. Twenty-one ACS modules are used for the acceleration. In addition, two ACS bunchers are used for longitudinal matching before the ACS acceleration, and two ACS debunchers are used to reduce the energy spread before the RCS injection. To summarize, total twenty-five ACS modules are necessary. The ACS cavities were installed in the summer shutdown period of 2013 [11]. Figure 1 shows the Linac accelerator tunnel after installation of the ACS cavities. After installation of the ACS cavities, we started high-power conditioning of the ACS cavities. Figure 2 shows the typical conditioning history of the ACS cavity. In the conditioning sequence, we put short pulse RF (50US) up to $2 \mathrm{MW}$ at first. Thereafter, we put longer pulse RF (600US) up to $2 \mathrm{MW}$. The average conditioning time for one ACS cavity is $149 \mathrm{~h}$. The detail conditioning sequence can be found in [12]. 


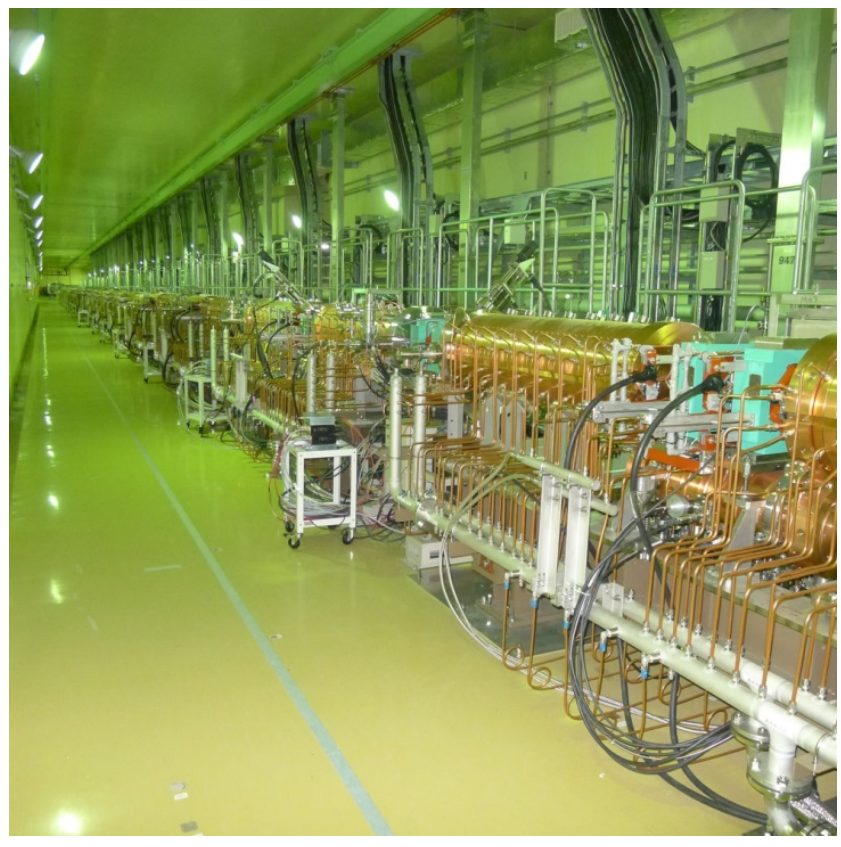

Figure 1. Linac accelerator tunnel after installation of ACS cavities

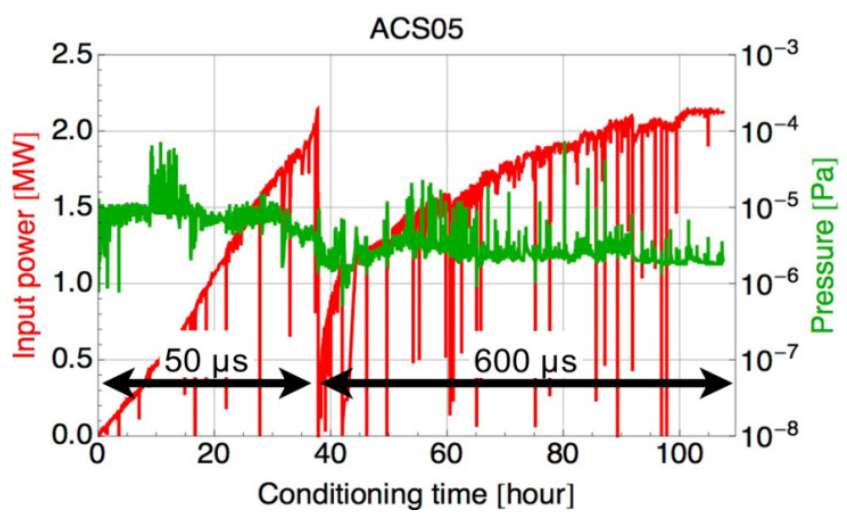

Figure 2. Typical conditioning history of ACS cavity [12]

\subsection{RCS}

In the RCS, the power supply for the injection shift bump magnets and the horizontal paint bump magnets was upgraded [13]. Those magnets traverse a painting orbit during injection [14]. A painting injection method is an ordinary way to reduce the space charge effect in a synchrotron [15-18]. The voltage of the power supply was increased by about twice according to increment of the Linac acceleration energy.

The shift bump power supply at the injection energy of $181 \mathrm{MeV}$ is of the IGBT (Insulated Gate Bipolar Transistor) chopper type [19]. It is composed of multiple IGBT assemblies, and its synthetic frequency is $48 \mathrm{kHz}$. A chopper system has the advantage of flexibility in terms of output waveform, and a similar system is adopted in another accelerator system [20,21]. It can generate arbitrary waveform currents, and we could establish all required injection orbits by using this system in the early days of the RCS commissioning. However, one problem of this type of power supply is its switching noise. The synthetic frequency of $48 \mathrm{kHz}$ and higher harmonics switching noises were observed on the output current monitor and also by means of search coils set inside the magnets. As a result, the beam orbit was shaken by the magnetic field distortion, and a $100 \mathrm{kHz}$ orbit ripple was observed by the beam position monitor. This ripple source was certainly originated from the power supply, but the magnets (a load of the power supply) also seemed to enhance the noise [22]. Therefore we developed a new, low-ripple shift bump power supply system considering replacement of the injection system with higher injection energy [23]. The new power supply was designed based on a capacitor bank scheme, and it has lower switching times to generate a trapezoidal current pattern. Thus, switching noise is suppressed well compared to old system. The maximum required current is $32 \mathrm{kV}$, and voltage is $14.4 \mathrm{kV}( \pm 7.2 \mathrm{kV})$, as defined based on the magnet inductance and the fast rise/fall time of $150 \mu$ s [24].

The paint bump power supply is also of the same type as the old shift bump magnet, namely, IGBT chopper type. This IGBT chopper type is very suitable for generating arbitrary painting orbit patterns, and its required voltage is not as high as that of the shift bump. Therefore, noise is lower than that of the shift bump system and is at an acceptable level. Thus, the faster switching IGBT assembly is adopted continuously for the paint bump power supply [25]. Its synthetic frequency is $600 \mathrm{kHz}$, and fast beam oscillation is not observed.

We checked the new shift bump power supply before continuous operation, and a malfunction was occurred. The diodes in the flattop unit, which works to keep the flatness of the waveform current, were frequently out of order. Owing to the defect of this unit, we were not able to keep the flatness of the waveform current and the flattop region of the shift bump current had a slope [26]. This induced beam orbit shift during injection. Figure 3 shows the magnetic field pattern defect of the shift bump magnet, and the orbit shift due to the defect is shown in figure 4 .

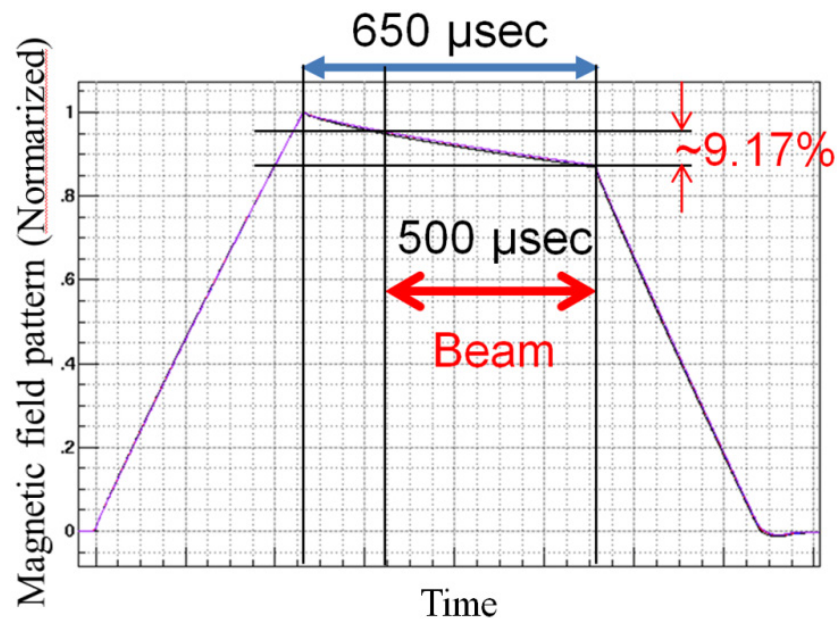

Figure 3. Magnetic field pattern of shift bump magnet. When normal, the magnetic field during injection period should be flat. However, it has a slope and decreases $9.17 \%$ during injection period. 


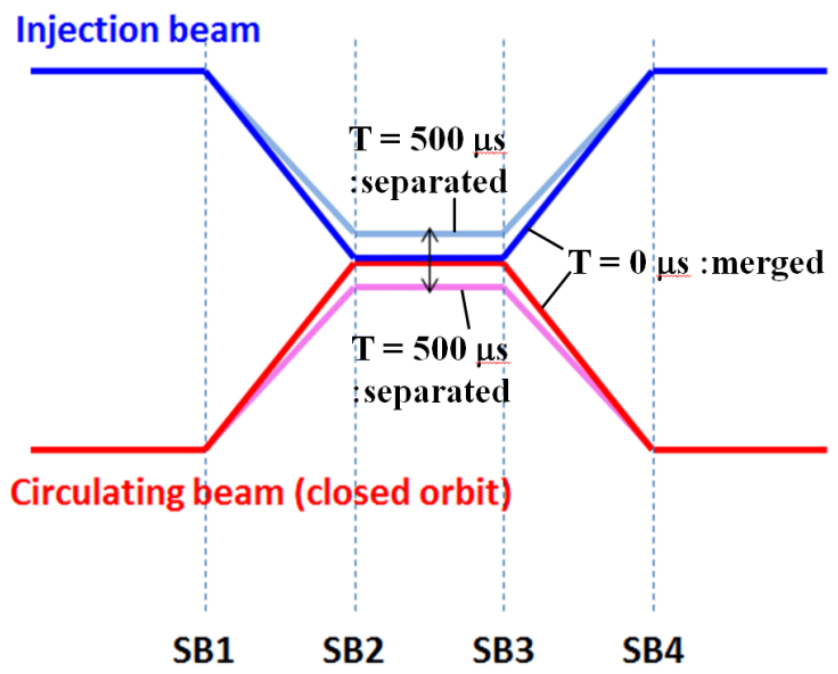

Figure 4. Orbit shift due to defect of shift bump field. Four shift bump magnets excite one power supply, and these magnetic fields cause the injection and the circulating orbits to merge. Due to slope of the magnetic field pattern, the injection and the circulating beams are separated from each other.

For the moment, we compensated for this orbit shift by using the other magnets. Four paint bump magnets (PBH1-4) were used to correct the shift of the circulating beam orbit, and two pulse steering magnets (PSTR1, 2) were used to correct the shift of the injection beam orbit respectively. Figure 5 shows the current waveforms of the injection magnets for compensation, and the injection orbits before and after correction are shown in figure 6 . Owing to this countermeasure, we were able to start beam commissioning with $400 \mathrm{MeV}$ injection energy.

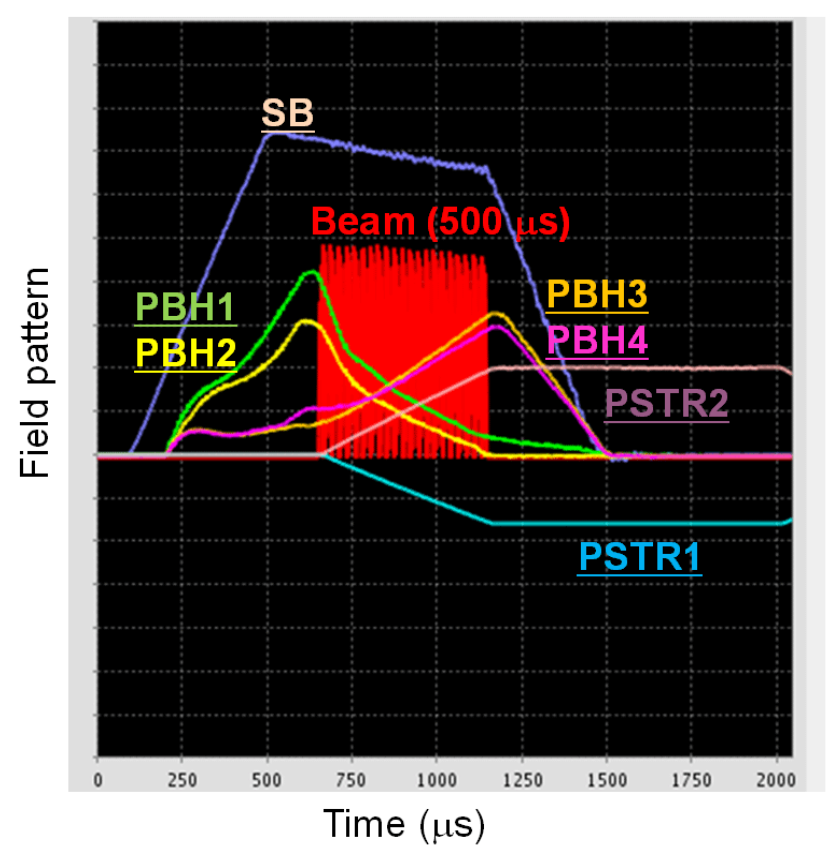

Figure 5. Current waveforms of injection magnets for orbit correction

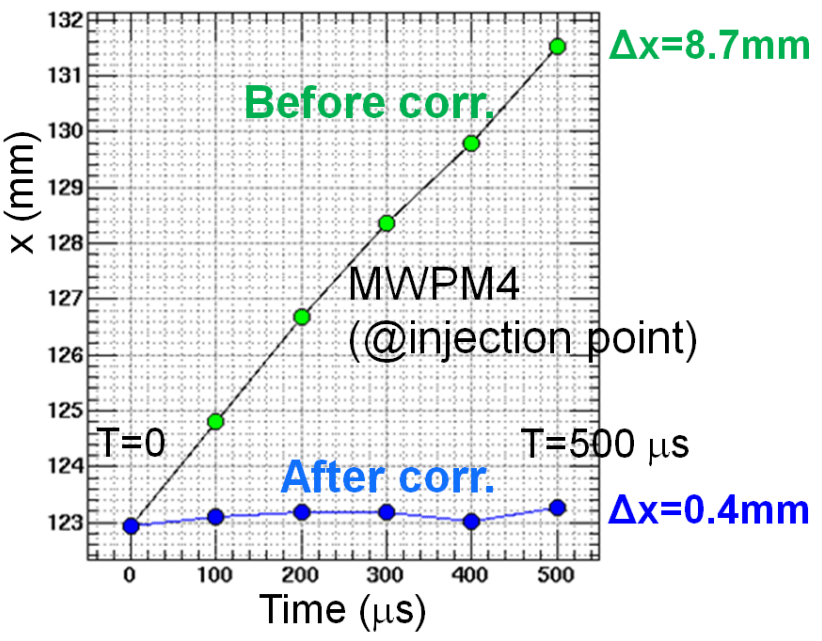

Figure 6. Injection orbit shift before and after correction

\subsection{Commissioning with $400 \mathrm{MeV}$ Linac}

Beam commissioning with the new ACS cavities was carried out from December 2013 to January 2014. Thereafter, we achieved acceleration energy of $400 \mathrm{MeV}$ on January 17, 2014 [27]. Then, we started user operation at the acceleration energy of $400 \mathrm{MeV}$, but we need additional study time to mitigate some issues. The first issue is halo formation in the ACS section. This halo causes beam loss in the RCS. Proper matching by means of additional longitudinal monitors is needed. The other issue is high radioactivity at some points in ACS section. To solve these issues, we continue the Linac beam study.

From the Laslett tune shift equation, the magnitude of space charge tune shift is proportional to $\beta^{2} \gamma^{3}$, where $\beta$ and $\gamma$ are the Lorentz factor [28]. This indicates that the amount of space charge tune shift with injection energy of $400 \mathrm{MeV}$ is considerably smaller than that with injection energy of $181 \mathrm{MeV}$. We investigated the effect of injection energy upgrade, and the result demonstrated that beam loss due to space charge tune shift was reduced to an acceptable level [29]. We confirmed the effect of injection energy upgrade.

\section{Ion Source Upgrade in Summer Shutdown 2014}

\subsection{Linac}

In summer shutdown period of 2014, we improved many accelerator components of the Linac and RCS. The most important improvement in the Linac is replacement of the front-end system with one having a higher peak current. Figure 7 shows the new front end system. The front-end system consists of a new ion source, new Radio Frequency Quadrupole (RFQ), and some parts of a beam transport line between the new ion source and new RFQ. A cesium-free negative hydrogen ion source driven with a lanthanum 
hexaboride filament had been used since the Linac operation began in 2006 [30]. Although it satisfied the initial stage requirement of $30 \mathrm{~mA}$ in J-PARC, it was proven that this current level did not increase by cesiation. Thus, we have newly developed a cesiated RF-driven ion source to satisfy the Linac upgrade requirements of $50 \mathrm{~mA}$ [31]. In the ion source, the source plasma is produced by a $2 \mathrm{MHz}$ RF discharge using an internal antenna that was developed at Spallation Neutron Source (SNS) at Oak Ridge National Laboratory [32]. New RFQ is optimized for the beam current of $50 \mathrm{~mA}$ [33].

The RF-driven $\mathrm{H}^{-}$ion source and new RFQ were checked on a test bench, which was constructed in the J-PARC Linac building. We checked various parameters of the test bench [34], and we tried long-term continuous operation of this system [35]. Figure 8 shows the test results of long-term operation. Finally, we achieved $683 \mathrm{~h}$ (about 1 month) of continuous operation. However, RFQ discharge occurred frequently during the long-term operation test. Therefore, we decided to install an additional pump in the actual beam line and keep conditioning it as and when possible.

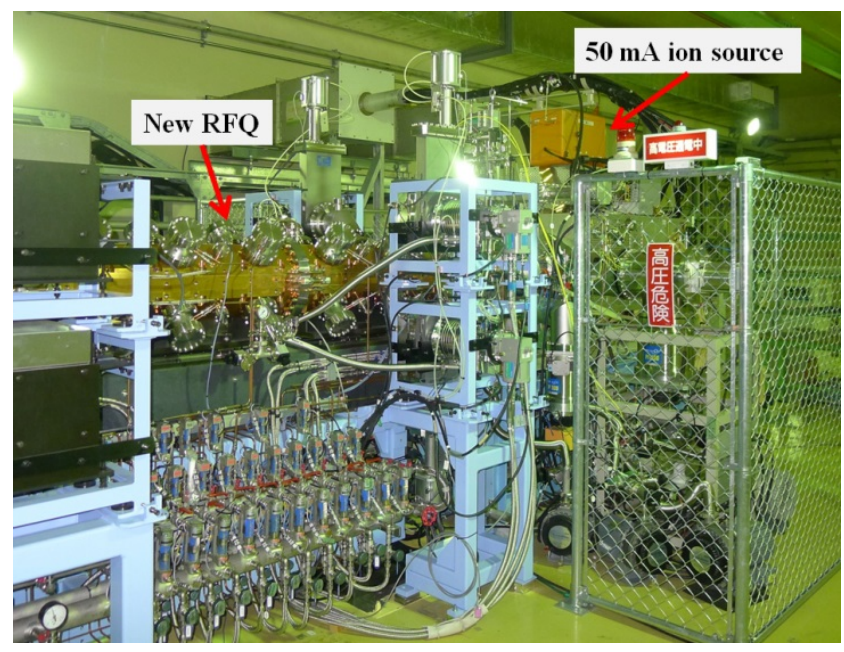

Figure 7. New front end system

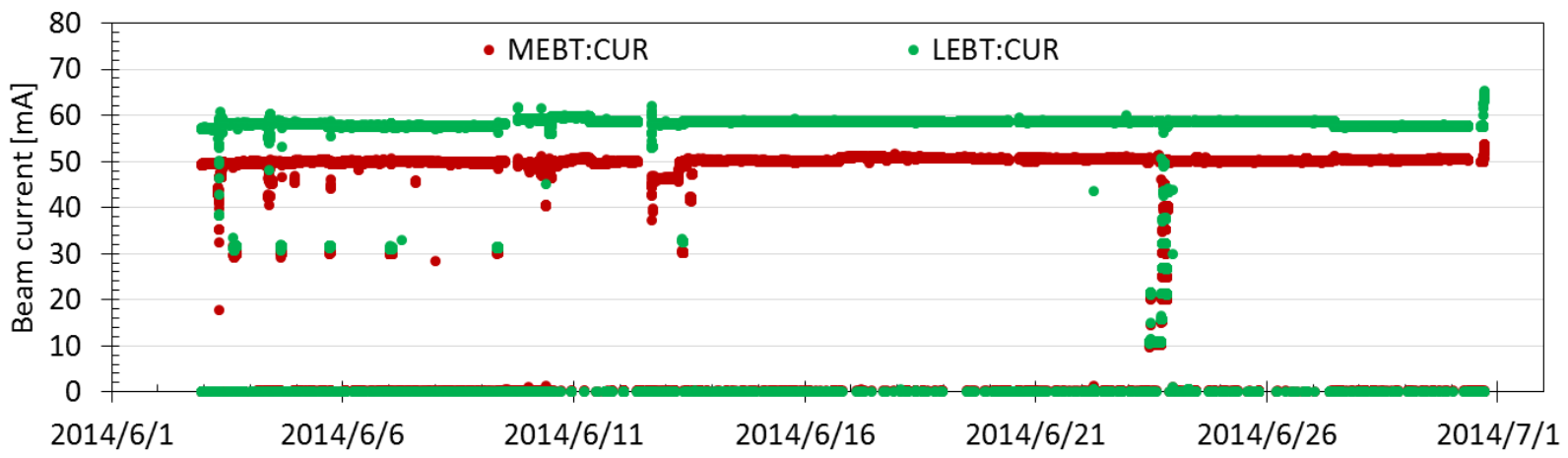

Figure 8. Result of long-term operation test. There were some beam studies with low peak current during this long-term operation test. 


\subsection{RCS}

The problem of shift bump power supply system was solved in the shutdown period of 2014, and we were able to keep the flat top of the magnetic field at an adequate level. The shift bump power supply used to trip frequently owing to overheating. To solve this issue, we installed additional cooling fans on the housing frame. Herewith, the inside of power supply housing was cooled and the system stabilized [36].

\section{Commissioning Towards 1-MW Output Beam}

We started beam commissioning of the Linac using the new front end system toward the end of September 2014 after maintenance work in the summer. The Linac beam commissioning progressed smoothly, and a 1-MW trial of the RCS was started in the middle of October.

In this trial, we chose the same parameters as those during user operation; betatron tune is $(6.45,6.42)$, and second harmonic RF is superimposed on the fundamental $\mathrm{RF}$. Injection beam momentum is offset from synchronous momentum, and transverse painting area is $100 \pi \mathrm{mm} \mathrm{mrad}$. The trial was started from the beam current of $380 \mathrm{~kW}$ equivalent, and the current was increased gradually to $770 \mathrm{~kW}$ equivalent. We could accelerate without remarkable losses under these conditions. However, the RF system tripped suddenly when we increased the current to $820 \mathrm{~kW}$ equivalent (see figure 9). We investigated the cause of this trip and found that the required anode current surpassed the interlock level when the beam intensity was over $800 \mathrm{~kW}$ [37]. In the RCS, the multi-harmonic feed-forward method ( $\mathrm{h}=2,4$, and 6) was employed for beam loading compensation [38]. Therefore, it was difficult to estimate the required anode current precisely. Figure 10 shows the required anode current of various conditions. The red dotted line in figure 10 corresponds to the interlock level for the anode current at this point, and the red circles denote the required anode current measured in the 1-MW trial. Thus, the required anode current exceeded the interlock level when the beam current was $820 \mathrm{~kW}$ equivalent.

Since we were not able to accelerate to more than the $800 \mathrm{~kW}$ equivalent beam in this situation, we decided to increase the resonant frequency of the RF cavity, which had been set to $1.7 \mathrm{MHz}$. This is because impedance of the cavity becomes more inductive upon increasing the resonant frequency. At the higher resonant frequency (more inductive) cavity, the wake field caused by the beam current pushes up the acceleration voltage. Therefore, the required anode current to maintain the acceleration voltage is reduced. Thus, we removed the capacitors from the cavities and raised the resonant frequency from $1.7 \mathrm{MHz}$ to $2.1 \mathrm{MHz}$. In addition, the interlock level was turned up to use the entire margin of anode power supply (from 110A to 125A).
The blue line in figure 10 is a new interlock level, and the blue squares show the required anode current of the $2.1 \mathrm{MHz}$ resonant frequency system. After these quick measures, we successfully achieved 1-MW beam acceleration in January, 2015 [39].

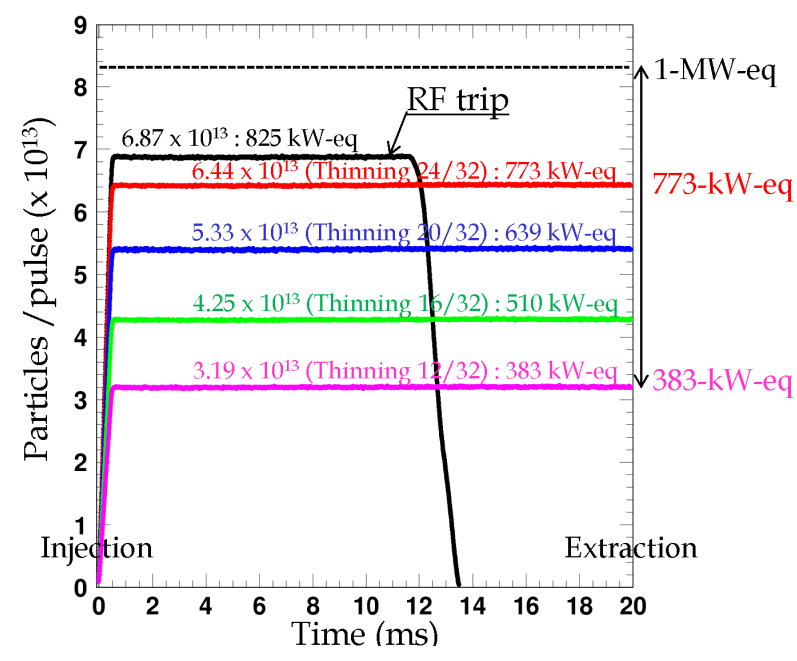

Figure 9. Beam survival of first trial [37]

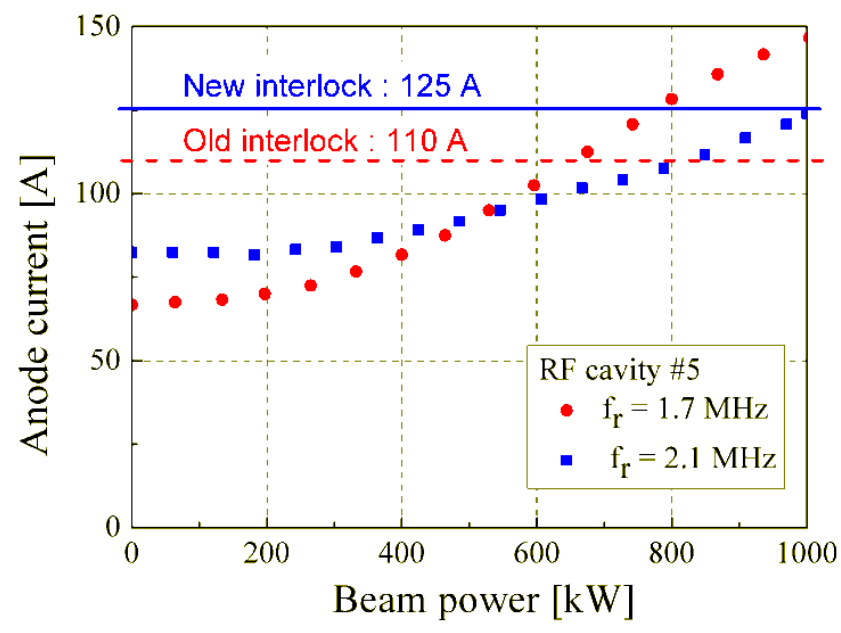

Figure 10. Anode current dependence on beam power

\section{Conclusions}

To achieve 1-MW output power, improvements were made to the J-PARC Linac and the RCS. The acceleration energy of the Linac was raised to $400 \mathrm{MeV}$ by installing a new acceleration cavity in the summer of 2013, and the front end was replaced in the summer of 2014 to increase the peak Linac current to $50 \mathrm{~mA}$. The injection system of the RCS was upgraded simultaneously to accept a $400 \mathrm{MeV}$ injection beam. As a result, we successfully achieved 1-MW beam acceleration in January, 2015. Major components of beam loss in the RCS, which caused by the space charge effect, were well minimized by the injection energy upgrade and the injection painting scheme. For the 
moment, the remaining beam loss is mainly from foil scattering during charge-exchange injection. To achieve stable 1-MW user operation, we continue to improve the accelerator system.

\section{REFERENCES}

[1] Y. Yamazaki (edit.). Accelerator Technical Design Report for J-PARC, KEK-report 2002-13, 2002.

[2] F. Naito. Present status of J-PARC, Asian Particle Accelerator Conference 2007, MOXMA01, 2007.

[3] M. Ikegami. Progress in the Beam Commissioning of J-PARC Linac and its Upgrade Path, 24th Linear Accelerator Conference, MO201, 2008.

[4] K. Hasegawa, H. Asano, E. Chishiro, T. Hori, T. Ito, T. Kobayashi, Y. Kondo, Y. Namekawa, H. Oguri, K. Ohkoshi, H. Suzuki, A. Ueno, M. Yamazaki, S. Anami, Z. Fang, Y. Fukui, K. Ikegami, M. Kawamura, F. Naito, K. Nanmo, H. Tanaka, S. Yamaguchi. Operating experience of the J-PARC Linac, TCSET of the International Conference, 24th Linear Accelerator Conference, MOP004, 2008.

[5] H. Hotchi. Status of J-PARC commissioning, 42nd ICFA advanced beam dynamics workshop on High-Intensity and High- Brightness Hadron Beams HB2008, OPL02, 2008.

[6] M. Kinsho. Status of the J-PARC $3 \mathrm{GeV}$ RCS, 23rd Particle Accelerator Conference, TU6PFP065, 2009.

[7] K. Yamamoto. J-PARC recovery status, 52nd ICFA advanced beam dynamics workshop on High-Intensity and HighBrightness Hadron Beams HB2012, MOI1A02, 2012.

[8] T. Koseki, K. Hasegawa. Present status of J-PARC after the shutdown due to the radioactive material leak accident-, 5th International Particle Accelerator Conference, THPME061, 2014

[9] H. Ao, Y. Yamazaki. First high-power model of the annular-ring coupled structure for use in the Japan Proton Accelerator Research Complex Linac, Physical Review Special Topics -Accelerators and Beams, Vol.15, 011001, 2012.

[10] H. Ao, A. Ueno, K. Hirano, H. Asano, T. Morishita, K. Hasegawa, Y. Yamazaki. First annular-ring coupled structure cavity for the Japan Proton Accelerator Research Complex Linac, Physical Review Special Topics Accelerators and Beams, Vol.15, 051005, 2012.

[11] K. Hasegawa. Commissioning of energy upgraded Linac of J-PARC, 27th Linear Accelerator Conference, TUIOB03, 2014.

[12] H. Ao, J. Tamura, Y. Nemoto, T. Ito, N. Ouchi, Z. Fang, K. Futatsukawa, K. Nammo, T. Sugimura, H. Asano. High power conditioning of annular-ring coupled structures for the J-PARC Linac, 27th Linear Accelerator Conference, THPOL07, 2014.

[13] N. Hayashi, H. Harada, K. Horino, H. Hotchi, J. Kamiya, M. Kinsho, P.K. Saha, Y. Shobuda, T. Takayanagi, N. Tani, T. Togashi, T. Ueno, M. Watanabe, Y. Watanabe, K. Yamamoto,
M. Yamamoto, Y. Yamazaki, M. Yoshimoto, Y. Irie, T. Toyama. Progress of Injection Energy Upgrade Project for J-PARC RCS, 4th International Particle Accelerator Conference, THPWO032, 2013

[14] H. Harada. Accelerator Technical Design Report for J-PARC, KEK-report 2009-7, 2009.

[15] J. Galambos, S. Danilov, D. Jeon, J. Holmes, D. Olsen, SNS Injection Simulations with Space Charge, 18th Particle Accelerator Conference, 1999.

[16] B. Jones, D. Adams, C. Warsop, Injection Studies on the ISIS Synchrotron, 22nd Particle Accelerator Conference, TUPAN113, 2007.

[17] M.Y. Huang, S. Wang, W.B. Liu, J. Qiu, L.S. Huang, Study on the Injection Beam Commissioning Software for CSNS / RCS, 6th International Particle Accelerator Conference, MOPTY006, 2015

[18] M. Cieslak-Kowalska, J. Abelleira, E .Benedetto, C. Bracco, Evolution of High Intensity Beams in the CERN PS Booster after $\mathrm{H}^{-}$Injection and Phase Space Painting, 7th International Particle Accelerator Conference, MOPOR024, 2016

[19] T. Takayana, J. Kamiya, M. Watanabe, Y. Yamazaki, Y. Irie, J. Kishiro, I. Sakai, T. Kawakubo, Design of the Injection Bump System of the $3-\mathrm{GeV}$ RCS in J-PARC, IEEE Transactions on applied superconductivity, Vol.16, No.2, pp1366-1369, 2006.

[20] L. Shen, Y. L. Chi, C. Huang, The Pulsed Power Supply Using IGBT Topology for CSNS Injection System Bump Magnet, 22nd Particle Accelerator Conference, WEPMN044, 2007.

[21] F. Long, Status and Trends in Magnet Power Converter Technology for Accelerators, 5th International Particle Accelerator Conference, THYB01, 2014

[22] Y. Shobuda, Y. Irie, S. Igarashi. Analytical method for the evaluation of field modulation inside the RF-shielded chamber with a time-dependent dipole magnetic field, Physical Review Special Topics Accelerators and Beams, Vol.12, 032401, 2009.

[23] T. Takayanagi, N. Hayashi, T. Ueno, T. Togashi, Y. Irie. Simulation Model for Design of a New Power Supply, IEEE Transactions on applied superconductivity, Vol.22, No.3, 5400704, 2012.

[24] T. Takayanagi, N. Hayashi, M. Kinsho, T. Ueno, T. Togashi, K. Horino, Y. Irie. Design and Preliminary Performance of the New Injection Shift Bump Power Supply at the JPARC $3 \mathrm{GeV}$ RCS, IEEE Transactions on applied superconductivity, Vol.24, No.3, 0503504, 2014.

[25] T. Ueno, T. Takayanagi, K. Horino, N. Hayashi, M. Kinsho. Status of the horizontal paint bump power supply of the J-PARC RCS, 11th Annual Meeting of Particle Accelerator Society of Japan, PASJ2014-SUP058, 2014(in Japanese).

[26] T. Takayanagi, T. Ueno, K. Horino, N. Hayashi, M. Kinsho, K. Okabe, Y. Irie. Development and Present Status of New Horizontal Shift Bump Power Supply for Injection Bump at the J-PARC RCS, 11th Annual Meeting of Particle Accelerator Society of Japan, PASJ2014-SUP059, 2014(in Japanese). 
[27] T. Maruta, K. Futatsukawa, Y. Liu, T. Miyao, A. Miura, H. Sako, M. Ikegami. Recent progress of beam commissioning at J-PARC Linac, 27th Linear Accelerator Conference, THPF040, 2014.

[28] L. J. Laslett. On Intensity Limitations Imposed by Transverse Space-charge Effects in Circular Particle Accelerators, Summer Study on Storage Rings, BNL-7534, 324-367, 1963

[29] H. Hotchi. Commissioning the $400 \mathrm{MeV}$ Linac at J-PARC and High Intensity Operation of the J-PARC RCS, 5th International Particle Accelerator Conference, TUXA01, 2014

[30] H. Oguri, A. Ueno, K. Ikegami, Y. Namekawa, K. Ohkoshi, Status of the Japan Proton Accelerator Research Complex Hion source, Physical Review Special Topics-Accelerator and Beams, Vol.12, 010401, 2009.

[31] A. Ueno, I. Koizumi, K. Ohkoshi, K. Ikegami, A. Takagi, S. Yamazaki, H. Oguri, Dependence of beam emittance on plasma electrode temperature and RF-power, and filter-field tuning with center-gapped rod-filter magnets in J-PARC $\mathrm{RF}$-driven $\mathrm{H}^{-}$ion source, Review of Scientific Instruments, Vol.85 02B133, 2013.

[32] M. P. Stockli, B. Han, S. N. Murray, T. R. Pennisi, M. Santana, R. F. Welton, Ramping up the Spallation Neutron Source beam power with the $\mathrm{H}^{-}$source using $0 \mathrm{mg} \mathrm{Cs} /$ day, Review of Scientific Instruments, Vol.81 02A729, 2010.

[33] Y. Kondo, K. Hasegawa, T. Morishita, R. A. Jameson. Beam dynamics design of a new radio frequency quadrupole for beam-current upgrade of the Japan Proton Accelerator
Research Complex Linac, Physical Review Special Topics -Accelerators and Beams, Vol.15, 080101, 2012.

[34] Y. Kondo, T. Morishita, S. Yamazaki, T. Hori, Y. Sawabe, A. Takagi. Beam test of a new RFQ for the J-PARC Linac, 27th Linear Accelerator Conference, MOPP091, 2014.

[35] T. Morishita, Y. Kondo, T. Hori, S. Yamazaki, K. Hasegawa, K. Hirano, H. Oguri, A. Takagi, T. Sugimura, F. Naito. High-power test results of the RFQ III in J-PARC Linac, 27th Linear Accelerator Conference, TUPP095, 2014.

[36] K. Horino, T. Takayanagi, T. Ueno, N. Hayashi, M. Kinsho Y. Irie. Report of the Temperature Problem of New Horizontal Shift Bump Power Supply at the J-PARC RCS, 11th Annual Meeting of Particle Accelerator Society of Japan, PASJ2014-SUP060, 2014(in Japanese).

[37] H. Hotchi. Lessons from 1-MW Proton RCS Beam Tuning, 54th ICFA advanced beam dynamics workshop on High-Intensity and High- Brightness Hadron Beams HB2014, MOXLR02, 2014.

[38] F. Tamura, M. Yamamoto, C. Ohmori, A. Schnase, M. Yoshii, M. Nomura, M. Toda, T. Shimada, K. Hara, K. Hasegawa. Multiharmonic RF-feed forward system for beam loading compensation in wide-band cavities of a rapid cycling synchrotron, Physical Review Special Topics -Accelerators and Beams, Vol.14, 051004, 2011.

[39] H. Hotchi. Recent Progress of J-PARC RCS Beam commissioning -Toward Realizing the 1-MW Output Beam Power, 6th International Particle Accelerator Conference, TUBB3, 2015. 